\title{
Spiritual Health and Stress in Pregnant Women During the Covid-19 Pandemic
}

\author{
Reza Jafari Nodoushan ${ }^{1} \cdot$ Hadi Alimoradi ${ }^{1} \cdot$ Mahsa Nazari $^{1}$ (D)
}

Accepted: 9 October 2020 / Published online: 16 October 2020

(C) Springer Nature Switzerland AG 2020

\begin{abstract}
Stress is one of the effective factors in the occurrence of negative effects during pregnancy that can cause adverse outcomes such as preterm delivery and reduced intrauterine growth of the fetus in pregnant women. Therefore, one of the serious concerns during the COVID-19 pandemic is the physical health and mental health of pregnant women. This study aimed to evaluate the physical health status with the spiritual and mental health of pregnant women during the COVID-19 pandemic. The study is a descriptive study in 2019-2020 and the samples were randomly selected from all pregnant women who referred to hospitals and private maternity centers before and during the COVID-19 pandemic and performed all pregnancy and fetal health tests. It was performed on 560 pregnant female samples. The mental status of pregnant women was assessed using the DASS Spiritual Health and Stress Questionnaire. Data analysis was performed using SPSS statistical software (version 24). The results of this study showed that preterm birth, height, weight, and head circumference of babies and lungs and respiratory status of children with mental health and stress levels of pregnant women during the corona are significant compared with the previous of corona $(p<0.05)$. Increasing stress and decreasing the mental health of pregnant women during COVID-19 pandemic can increase the influencing factors in preterm delivery and unhealthy birth.
\end{abstract}

Keywords COVID-19 $\cdot$ Pandemic $\cdot$ Spiritual health $\cdot$ Pregnant women $\cdot$ Stress $\cdot$ Premature delivery

\section{Introduction}

In December 2019, release of a viral disease was reported in the city of Wuhan, China. The cause of this disease was a new and genetically modified virus from the family of coronaviruses called SARS 2-CoV, which was named COVID-19 disease [1]. The psychological effects of this viral

This article is part of the Topical Collection on Covid-19

Mahsa Nazari

m.nazari@stu.ssu.ac.ir

Reza Jafari Nodoushan

jafarinodoushan@gmail.com

Hadi Alimoradi

h.alimoradi@stu.ssu.ac.ir

1 Present address: Occupational Health Research Center, School of Public Health, Shahid Sadoughi University of Medical Sciences, Yazd, Iran disease on the mental health of people at different levels of society are of great importance [2]. Some psychological disorders, including stress experienced by women during pregnancy, can have adverse effects on childbearing outcomes. Among the adverse consequences of preterm delivery and weight loss at birth is because preterm delivery is one of the undesirable consequences of increasing the mortality rate of unborn babies and pregnant women [3]. At the beginning of 2020, many pregnant women due to epidemic COVID-19, in a state of quarantine exception to the living and the personal life and career and finances, are changed and many of them due to fear and stress. They have been quarantined in their homes for a long time due to infection and loss of fetus, and this can lead to affect women's emotional health. As depression and stress have been one of the symptoms of the prenatal period, but with the development of this viral disease, the adverse consequences of pregnant women and adverse infants were increased [4].

In recent years, most psychologists and specialists have emphasized the importance of spiritual health in the development and promotion of mental and emotional status of 
individuals and its necessity in individual and social life and consider it as one of the factors affecting the health of individuals. In defining spiritual health, the World Health Organization considers it as one of the influential dimensions of human life and the fourth basic dimension in promoting spirituality [5]. In today's world, one of the newest dimensions of health, apart from physical and mental health, is spiritual health. All aspects of health are meaningful in the form of spiritual health and lead to an increase in the quality of life [6]. Spiritual health plays a very important role in determining the health status of people and causes symptoms such as depression, loneliness, and meaninglessness in life. Spiritual health is one of the indicators related to stress relief and increasing the improvement score of a person's mental health [7].

One of the most important complications of preterm delivery in women is the birth of babies with inappropriate weight and outside the standard range. These babies suffer from unusual damage and unusual weight loss at birth and during their final development $[8,9]$. In developing countries and Iran, the prevalence of preterm labor is $25 \%$ and $34.9 \%$, respectively [9]. Pregnant women are exposed to stressful changes in the levels of their hormones, and these hormones cross the bloodbrain barrier and affect the growth rate of the fetus and can harm the fetus and at birth or growth weight or abnormal weight. Weight loss and sudden weight loss have reduced the safety of the baby's immune system and the release of neurotransmitters such as dopamine, serotonin, GABA, and norepinephrine has also been reported in infants who have been stressed during the fetal period [10]. One of the factors affecting the type of normal or premature birth in women is the amount of stress they receive during pregnancy and leads to disorders during and after childbirth in pregnant women such as depression and mood disorders and these effects on fetal health of infants [11], blood pressure (chronic) [12], infections at the episiotomy site [13], increasing the likelihood of unplanned cesarean delivery. Therefore, due to the changes made during pregnancy, the need for psychological adjustment in women is essential [14]. Stress is the most obvious sign in the behavior and clinical signs of pregnant women [15]. Because pregnant women undergo many physical and psychological changes during pregnancy, their impact on different life stresses during this period increases [16]. Pregnancy is one of the most stressful times for most women and is considered one of the most stressful times in a woman's life. The severity of stress in the last trimester is higher than in the first 6 months of pregnancy. Therefore, during this period, the chances of developing depression and anxiety-fear and stress-increase and most pregnant women experience these mood and mental disorders [17].

Pregnancy and childbirth are an important issue in women's lives, since women guarantee the mental health of the whole family and the baby that is born. In this research, the effect of Coronavirus on the rate of precocious and early delivery and stress in pregnant women who referred to Isfahan medical centers was investigated.

\section{Methods}

\section{Study Population and Design}

In this descriptive research, 620 pregnant women were selected using cluster random sampling method. The study population included pregnant women referring to Isfahan Private and Medical Hospital in 2019 and 2020. A total of 560 pregnant women had referred to these centers in Mani and a hospital in Isfahan for prenatal and delivery care. The sampling method was as follows: first, 10 centers out of 15 health centers were randomly selected by a simple lottery. The sample size was calculated based on a preliminary study with a reliability coefficient confidence $95 \%(\alpha=0.05)$ power of test $80 \%(\beta=$ 0.2 ) and the correlation coefficient formula was calculated. Questionnaires for people who could not read and complete the questionnaire were read and completed by health workers working in the centers. Not all people were eligible to participate in the study, and the study cost was considered for them, so that pregnant women were excluded from the study if they had a history of mental illness such as depression or inability to perform daily activities such as disability. In this study, three questionnaires of personal characteristics (age, level of education, occupation, gestational age, age of marriage), spiritual health, and stress anxiety and depression DASS were used. To prevent interfering factors before completing the questionnaires, pregnant women with drug addiction, a history of heart disease and high-risk pregnancy, a history of visiting a psychiatrist or psychologist, and taking medication or hospitalization mental illness were excluded.

\section{Questionnaires}

\section{Palutzian and Ellison Mental Health Questionnaire}

One of the related questionnaires for spiritual health is a 20 item questionnaire in which two dimensions of health are examined [18]. Ten questions of it belong to the dimension of religious health and 10 other questions examine the existential health of the individual. Religious and existential health questions are placed one by one in the questionnaire, and religious health begins with the individual's questions. The final score of this questionnaire is between 20 and 120 and it has a 6-point Likert scale. The final score of the questionnaire is divided into three distinct categories: $20-40$, average 4199 , and high 120-100. This study has been studied by Farahani Nia in Iran [19]. In Seyedfatemi et al., validity spiritual health through credit specific content and reliability 
through Cronbach's alpha reliability coefficient was determined to be 82.0 [20].

\section{Stress-Anxiety-Depression Questionnaire (DASS-21)}

In 1995, Lavibund designed a 21-item, 3-item questionnaire to assess stress, anxiety, and depression. Each component of this questionnaire had 7 questions [21]. In 2007 in Iran by Samani and Jokar, 21 DASS questionnaires were evaluated to determine validity and reliability. The scores of confidence limits for each component of the questionnaire including depression, anxiety, and stress are $0.80,0.76$, and 0.77 , respectively, with Cronbach's alpha coefficient variable for the same components in the above equations of $0.81,0.74$, and 0.78 , respectively [22].

\section{General Self-Efficacy Questionnaire}

One of the effective questionnaires in the field of self-efficacy is Sheerer Scale questionnaire [23]. The Self-Efficacy Questionnaire has 17 questions that are used as 5-point Likert and reverse [24]. The highest and in fact the quorum for this questionnaire is 85 and the minimum is 17 narrative in Iran. Its reliability was obtained by internal consistency and the new test of 0.83 [25].

\section{Data Analysis}

The questionnaires were completed by pregnant women after explaining the objectives of the research and the satisfaction of the samples with the guidance of the questioner and in the form of a self-report. Data were analyzed using SPSS software (Version 24) and analysis of variance. The significance level of this study was considered to be 0.05 .

\section{Results}

In this study, the selected age group with the highest percentage (41.78\%) includes 25-30 years. Among the types of jobs in women, those who worked at home had the highest percentage (90.5\%). In terms of education level, about half of the women had primary education. Most women in this study were in the last months of pregnancy and their average age at marriage was $25-30$ years $(52.4 \%)$.

Also, in the results, the mean score of spiritual health of pregnant women $99.13 \pm 14.21$ compared with the total score of 560 shows that about $43.3 \%$ of women had a normal with average score level of spiritual health and about $10.3 \%$ shows increasing level of spiritual health and the others appeared with a lowering level of spiritual health.. Also, the results of the study showed that the average score of religious health $(51.3 \pm 7.75)$ is higher than existential health $(47.8 \pm 7.40)$.
The relationship between contextual and demographic variables and spiritual health was studied unilaterally and the results are listed in Table 1.

Based on Scheffe statistical method, the score of spiritual health in terms of occupation, a month of pregnancy, and age of marriage was a significant difference. The use of the Scheffe test showed that there was a significant difference in spiritual health with housewives, self-employed people ( $p=$ 0.05 ). Also, spiritual health in people with a marriage age of more than 30 years was significantly different from that of people less than 25 years of age that was higher $(p<0.001)$.

The result shows that the mean self-efficacy score in pregnant women was $63.7 \pm 8.84,50.5 \%$. The ranking of the subjects had low self-efficacy, $45 \%$ had moderate self-efficacy, and $4.50 \%$ had high self-efficacy. The effect of demographic variables on self-efficacy was investigated using a one-way analysis of variance (Table 1).

This result showed that self-efficacy score was significantly different according to age, time of marriage, and month of pregnancy. The use of the Scheffe test showed that the selfefficacy score in women over 30 years of age was significantly higher than women under 25 years of age $(p=0.024)$. Also, the rate of self-efficacy in the second trimester of pregnancy was significantly higher. Significance was higher than selfefficacy in the first quarter $(p=0.014)$.

The independent and dependent variables in this study are spiritual health and self-efficacy, respectively. Because of the heterogeneity between the independent and dependent variables, the preferred statistical method is simple linear regression. Kolmogorov test showed that the dependent variable was normal $(p=0.046)$ (Table 2).

The relative frequency of stress and its related components in pregnant women is shown in Table 3. Of 560 pregnant women, $35.31 \%$ were in the upper range, $44.64 \%$ were women in the moderate stress range, $25 \%$ were in the high range, and during the coronavirus epidemic. Between stress and level of education $(P<0.05)$ and employment $(P<0.05)$, significant difference was achieved, while between stress and socioeconomic status $(P=1.03)$ and age $(P=0.85)$, it was not significant.

\section{Discussion}

The corona virus (COVID-19) has challenged people of all ages in the whole world. One of the most important concerns of COVID-19 is in pregnant women and newborns [26]. Pregnancy is most important periods of every woman's life and it is considered as stressful and challenging periods for women [27]. Most of the pregnant women have moderate and high spiritual health scores, which is acceptable due to the high level of religious beliefs in Iran. According to most studies conducted in Iran, the normal state of spiritual health of 
Table 1 Distribution of mean \pm SD of self-efficacy, spiritual health and stress in pregnant women in terms of demographic variables during the corona epidemic

\begin{tabular}{llllll}
\hline Demographic variable & & Percentage & Efficacy mean \pm SD & Spiritual health mean \pm SD & Stress mean \pm SD \\
\hline Age (years) & Less than 25 & $22.11 \%$ & $63.52 \pm 5.48$ & $95.6 \pm 5.48$ & $40.23 \pm 5.48$ \\
& $25-30$ & $41.78 \%$ & $63.81 \pm 8.45$ & $98.52 \pm 8.45$ & $38.5 \pm 8.45$ \\
Education & More than 30 & $36.11 \%$ & $62.35 \pm 7.49$ & $96.5 \pm 7.49$ & $40.5 \pm 7.49$ \\
& Illiterate & $15.38 \%$ & $66.5 \pm 3.25$ & $90.2 \pm 3.25$ & $51.2 \pm 3.25$ \\
& Elementary & $15.32 \%$ & $64.2 \pm 2.25$ & $101 \pm 2.25$ & $55.3 \pm 2.25$ \\
& Diploma & $57.8 \%$ & $64.8 \pm 3.12$ & $97.8 \pm 3.12$ & $52.6 \pm 3.12$ \\
Job & University & $11.50 \%$ & $63.8 \pm 4.15$ & $99.7 \pm 4.15$ & $51.3 \pm 4.15$ \\
& Housewife & $90.5 \%$ & $60.5 \pm 3.47$ & $94.3 \pm 3.47$ & $48.9 \pm 3.47$ \\
& Employee & $5.6 \%$ & $61.4 \pm 3.69$ & $97.7 \pm 3.69$ & $45.6 \pm 3.69$ \\
Month of pregnancy & Free & $3.9 \%$ & $62.3 \pm 4.12$ & $94.6 \pm 4.12$ & $47.8 \pm 4.12$ \\
& First quarter & $17.9 \%$ & $61.8 \pm 7.85$ & $93.2 \pm 7.85$ & $50.2 \pm 7.85$ \\
& Second quarter & $33.6 \%$ & $62.5 \pm 6.35$ & $95.2 \pm 6.35$ & $52.3 \pm 6.35$ \\
Marriage age (years) & Third quarter & $48.5 \%$ & $63.4 \pm 6.14$ & $99.12 \pm 6.14$ & $55.6 \pm 6.14$ \\
& Less than 25 & $31.3 \%$ & $62.78 \pm 8.6$ & $104.13 \pm 8.6$ & $54.2 \pm 8.6$ \\
& 25-30 & $52.4 \%$ & $62 \pm 8.1$ & $101.6 \pm 8.1$ & $55.2 \pm 8.1$ \\
& More than 30 & $16.3 \%$ & $62.83 \pm 9.3$ & $99.17 \pm 9.3$ & $54.1 \pm 9.3$ \\
\hline
\end{tabular}

women was in a high proportion, but in the conditions of COVID-19, the desirability of spiritual health in women has decreased.

The study of Rezaei et al. in Iran also reported a similar result, including high levels of spiritual health in Iranian women [28]. In the study of Mehrabi et al., mean of the spiritual health rank in women with breast cancer and infertile reported to be 95 and $97.7 \%$, respectively [29]. The results of McCobry's study with the present study have a significant and direct relationship with spiritual health and age, level of education [30]. Another cross-sectional study in Iran was done by Leili Salehi that was performed on 222 pregnant women in a hospital. Eligible individuals were enrolled through convenience sampling and data were collected using five questionnaires including COVID-19 Fear Scale, COVID-19 Anxiety Scale, Pregnancy Experience Scale, Depression Anxiety Stress Scale, and Demographic Checklist. According to the results of path analysis, COVID-19 anxiety and anxiety during pregnancy were variables that were directly and significantly related to mental health through only one pathway that was direct, and COVID-19 anxiety had the highest direct positive rate. Correlation between them is $B=0.32$. The next variable was happiness during pregnancy, which had a significant negative and direct relationship with mental health disorders $(B=0.29)$. In addition, fear of COVID-19 was shown to have a positive and significant relationship with mental health through an indirect pathway through mediated concerns about pregnancy experiences $(B=0.05)$ and with the effects of COVID-19 on health. Psychosis and anxiety are consistent in the present study [31].

According to the study published by Adegbola, selfefficacy shows a positive and significant relationship with spirituality and somehow supports the results of the study that spiritual health is related to the religious and existential

Table 2 Investigating between spiritual health and its dimensions with independent variables during the COVID-19 epidemic

\begin{tabular}{|c|c|c|c|c|c|c|}
\hline Independent variables & $\begin{array}{l}\text { The correlation coefficient } \\
(r)\end{array}$ & $\begin{array}{l}\text { The coefficient of determination } \\
\left(r^{2}\right)\end{array}$ & Beta & $B$ & CI $95 \%$ & $p$ \\
\hline Spiritual health & 0.788 & 0.628 & 0.767 & 0.485 & $0 / 430-0 / 535$ & $<0.001$ \\
\hline Existential health & 0.793 & 0.654 & 0.741 & 0.541 & $0 / 834-1 / 036$ & $<0.001$ \\
\hline Religious health & 0.799 & 0.457 & 0.625 & 0.418 & $0 / 665-0 / 893$ & $<0.001$ \\
\hline Stress during the first 3 months of pregnancy & 0.655 & 0.415 & 0.589 & 0.456 & $0 / 717-0 / 905$ & $<0.45$ \\
\hline $\begin{array}{l}\text { Stress during the second of } 3 \text { months of } \\
\text { pregnancy }\end{array}$ & 0.722 & 0.521 & 0.625 & 0.415 & $0 / 610-0 / 835$ & $<0.05$ \\
\hline $\begin{array}{l}\text { Stress during the third of } 3 \text { months of } \\
\text { pregnancy }\end{array}$ & 0.781 & 0.615 & 0.714 & 0.589 & $0 / 865-0 / 1003$ & $<0.001$ \\
\hline
\end{tabular}

Significance level of the test $p<0.05$ 
Table 3 Investigating the frequency distribution of pregnancy outcomes in women and infants during the outbreak of COVID-19

\begin{tabular}{|c|c|c|c|}
\hline Variable & Type of variable & Percent & Significant level $(P)$ \\
\hline \multirow[t]{2}{*}{ Preterm delivery } & Normal & $69.46 \%$ & $P<0.05$ \\
\hline & Unusual & $30.54 \%$ & $P=0$ \\
\hline \multirow[t]{2}{*}{ High stress } & Anxiety & $31.6 \%$ & $P<0.05$ \\
\hline & Depression & $22.4 \%$ & $P=0.064$ \\
\hline \multirow[t]{2}{*}{ Moderate stress } & Anxiety & $15.65 \%$ & $P<0.05$ \\
\hline & Depression & $13.32 \%$ & $P=0.079$ \\
\hline \multirow[t]{2}{*}{ Low stress } & Anxiety & $8.9 \%$ & $P<0.05$ \\
\hline & Depression & $8.18 \%$ & $P=0.065$ \\
\hline \multirow[t]{3}{*}{ Employment } & Housewife & $90.5 \%$ & $P<0.05$ \\
\hline & Employee & $5.4 \%$ & $P=0.01$ \\
\hline & Free & $4.1 \%$ & $P=0.01$ \\
\hline \multirow[t]{4}{*}{ Education } & Illiterate & $18.55 \%$ & $P<0.001$ \\
\hline & Elementary & $20.55 \%$ & $P=0.064$ \\
\hline & Diploma & $50.6 \%$ & $P<0.05$ \\
\hline & University & $10.3 \%$ & $P=0.079$ \\
\hline \multirow[t]{3}{*}{ Socioeconomic status } & $\mathrm{Bad}$ & $30.78 \%$ & $P=0.075$ \\
\hline & Good & $48.86 \%$ & $P<0.05$ \\
\hline & Excellent & $20.36 \%$ & $P=0.089$ \\
\hline \multirow[t]{3}{*}{ Age of pregnancy } & Less than 25 & $26.89 \%$ & $P=0.85$ \\
\hline & $25-30$ & $55.68 \%$ & $P<0.05$ \\
\hline & More than 30 & $17.43 \%$ & $P=0.056$ \\
\hline \multirow[t]{2}{*}{ Birth weight of baby } & Normal & $41.1 \%$ & $P<0.045$ \\
\hline & Unusual & $58.9 \%$ & $P<0.05$ \\
\hline \multirow[t]{2}{*}{ Height of baby birth } & Normal & $46.23 \%$ & $P<0.05$ \\
\hline & Unusual & $53.77 \%$ & $P<0.045$ \\
\hline \multirow[t]{2}{*}{ Around the head of baby birth } & Normal & $55.6 \%$ & $P<0.05$ \\
\hline & Unusual & $44.4 \%$ & $P<0.045$ \\
\hline
\end{tabular}

components of health [32]. Study by Rex et al. showed that performing religious and spiritual duties such as prayer is effective in increasing the level of self-belief and selfconfidence and can even increase the level of self-efficacy [33]. Also, the present study showed that spiritual health can predict self-efficacy. In this study, spiritual health and its dimensions were able to predict self-efficacy and the existing health had the highest effect on predicting self-efficacy of pregnant women. This result is consistent with the results of the Syed Imam study on the health status of students, which showed that it predicts spiritual health, self-efficacy, and selfesteem [34], but in the Elizabeth AN Wastnedge study, it was found that the clinical experience of complex pregnancies infected with other coronaviruses such as SARS and MERS made pregnant women more vulnerable to severe SARSCoV-2 infection and physiological changes during pregnancy. It has significant effects on the immune system, respiratory system, cardiovascular function, and blood coagulation. The indirect effects of the SARS epidemic on maternal health may even include complications such as reduced access to reproductive health services, increased stress, and increased socioeconomic deprivation. Therefore according to the type of study, the findings are not consistent with the present study [35].

The definition of pregnancy that expressed as a stressful period time for women and caused the fear, stress among pregnant women, and increased fear and anxiety due to acute respiratory disease COVID-19 reduces spiritual health, so this study is consistent with the present results [36]. Another study was done by Tom Farrell who conducted a cross-sectional study in Qatar in 2020 to examine the impact of COVID-19 and its associated limitations on perinatal mental health in women. The data including relevant demographic, pregnancy, and mental health history concerns, as well as stressors, were reviewed and showed a high prevalence of anxiety and depressive symptoms ( $34.4 \%$ and $39.2 \%$, respectively). There is a basis for scoring PHQ-ADS among pregnant women and it is consistent with the results of the present study [37]. Complications of labor are different for each woman, but in most of them, there was a high degree of stress and anxiety, leading to the birth of babies with special conditions like premature birth, low birth weight, nausea, and vomiting [27, 38]. 
To confirm the results of the present study, we can refer a study that was conducted by Durankuş in 2020 and shown that the COVID-19 increases rate of depression, stress in pregnant women; so, the amount of stress and depression during the COVID-19 increased [38, 39]. A multinational cohort study was conducted in 2020 on all consecutive pregnant women with COVID-19 in 73 centers in 22 different countries. The results of the study showed that the mean gestational age at the time of diagnosis was $30.6 \pm 9.5$ weeks, of which $8.0 \%$ were women in the first trimester, $22.2 \%$ in the second, and $69.8 \%$ in the third trimester. Six abortions, 6 intrauterine IUDs, and 5 neonatal deaths, with an overall gestational mortality rate of 4.2 , thus lead to 17 experiments and 226 adverse fetal outcomes. Among 250 live neonates, 1 case $(0.4 \%)$ was positive in RT-PCR swab performed positively after delivery. The mother tested positive in the third trimester of pregnancy and the newborn was asymptomatic and had a negative RTPCR test after 14 days of life. Early gestational age at infection and low birth weight are the most important determinants of adverse perinatal outcomes in fetuses with maternal COVID19 infection. Conversely, the risk of vertical transmission appears to be negligible. The objectives of this study are generally to evaluate the gestational age and other factors affecting the incidence of infertile fetus and in line with the present study [40].

Facing a coronavirus epidemic has affected all members of society, especially pregnant women, stress and psychological problems and prevents the birth of healthy babies because most mothers experience premature birth due to quarantine conditions and increased stress, and their children. They are not natural. Finally, with increasing stress, the spiritual health of pregnant women decreases even in the religious and Islamic population of Iran, and this study needs to be reviewed worldwide to eliminate cultural influences as an intervening factor.

\section{Conclusion}

The aim of the research is to represent majority of pregnant women in the time of COVID-19 epidemic who had little spiritual health, and on the other hand, spiritual health and its dimensions were able to introduce self-efficacy as a known factor for behavior. Therefore, it is necessary to study more about the effects of spiritual health on the self-efficacy of pregnant women around the world to examine the effectiveness of the role of self-efficacy and spiritual health in stress changes in the COVID 19 viral crisis.

Acknowledgments The authors gratefully acknowledge Isfahan Private Hospital for their assistance in our access to cognitive data. We also acknowledge Shahid Sadoughi University of Medical Sciences because of administrative support of the work.
Authors' Contributions H. A participated in the study design, analysis, and wrote the manuscript. H. A \& RJ also conducted data collection. M.NZ also participated in the preparation of the draft of the paper, revised the draft of the manuscript, and supervised the project. M.NZ also conducted data analysis. All authors participated in the development of the manuscript and data interpretation. R. J participated in the study design, interpretation of findings, and also wrote the manuscript. All authors read and approved the final manuscript.

Data availability The data that support the analysis of this study (analysis codes and outputs) are available on request from the corresponding author (M.Nazari). The raw data are not publicly available due to institutional restrictions.

\section{Compliance with Ethical Standards}

Ethics Approval and Consent to Participate This study has been approved by the hospital and research center of Shahid Sadoughi University of Medical Sciences, which has an ethics committee (study ethics code: IR.SSU.SPH.REC.1399.134).

Before completing all the spiritual health and stress questionnaires of pregnant mothers, the informed consent questionnaire was completed to participate in the study.

Consent for Publication All authors agree to publish the article.

Competing Interests The authors declare that they have no conflict of interest.

Abbreviation DASS, Depression Anxiety and Stress Scale; GEQ, General Self-Efficacy Questionnaire

\section{References}

1. Zhao S, Chen H. Modeling the epidemic dynamics and control of COVID-19 outbreak in China. Quant Biol. 2020:1, 4, 12, 16, 22, $27,28,31,32$ and $35-40$. .

2. Li S, Wang Y, Xue J, Zhao N, Zhu T. The impact of COVID-19 epidemic declaration on psychological consequences: a study on active Weibo users. Int J Environ Res Public Health. 2020;17(6): 2032.

3. Goldenberg RL, Culhane JF, Iams JD, Romero R. Epidemiology and causes of preterm birth. Lancet. 2008;371(9606):75-84.

4. Grigoriadis S, Graves L, Peer M, Mamisashvili L, Tomlinson G, Vigod SN, et al. Maternal anxiety during pregnancy and the association with adverse perinatal outcomes: systematic review and meta-analysis. J Clin Psychiatry. 2018;79(5).

5. Organization WH. Promoting mental health: concepts, emerging evidence, practice: a report of the World Health Organization, Department of Mental Health and Substance Abuse in collaboration with the Victorian Health Promotion Foundation and the University of Melbourne: World Health Organization; 2005.

6. Allahbakhshian M, Jaffarpour M, Parvizy S, Haghani H. A survey on relationship between spiritual wellbeing and quality of life in multiple sclerosis patients. 6, 12, 20, 25, 27 and 29.

7. Oman D, Hedberg J, Downs D, Parsons D. A transcultural spiritually based program to enhance caregiving self-efficacy: a pilot study. Complement Health Pract Rev. 2003;8(3):201-24.

8. Makhoul IR, Awad E, Tamir A, Weintraub Z, Rotschild A, Bader $\mathrm{D}$, et al. Parental and perinatal factors affecting childhood anthropometry of very-low-birth-weight premature infants: a populationbased survey. Acta Paediatr. 2009;98(6):963-9. 
9. Marks KA, Reichman B, Lusky A, Zmora E, Network IN. Fetal growth and postnatal growth failure in very-low-birthweight infants. Acta Paediatr. 2006;95(2):236-42.

10. Senturk V, Abas M, Berksun O, Stewart R. Social support and antenatal depression in extended and nuclear family environments in Turkey: a cross-sectional survey. BMC Psychiatry. 2011;11(1): 48.

11. Karaçam Z, Ançel G. Depression, anxiety and influencing factors in pregnancy: a study in a Turkish population. Midwifery. 2009;25(4): 344-56.

12. Nikrahan GR, Kajbaf MB, Nouri A, Zarean E, Naghshineh E. Assessment of the relationship between personality traits, coping styles with stress and stress level in pregnant women. Iran J Obstet Gynecol Infertility. 2011;14(5).

13. Mulder EJ, Robles de Medina PG, Huizink AC, Van den Bergh BR, Buitelaar JK, Visser GH. Prenatal maternal stress: effects on pregnancy and the (unborn) child. Early Hum Dev. 2002;70(1-2):3-14.

14. Hamilton JG, Lobel M. Types, patterns, and predictors of coping with stress during pregnancy: examination of the revised prenatal coping inventory in a diverse sample. J Psychosom Obstet Gynaecol. 2008;29(2):97-104.

15. Ganji T, Einipour Z, Hosseini F. The relationship of pre-term delivery and stressful life events during pregnancy. Iran J Nurs. 2009;22(57):77-86.

16. Dareshouri MZ, Bosaknejad S, Sarvghad S. A survey on the effectiveness of stress management training with cognitive-behavioral group therapy approach on state/trait anxiety, pregnancy anxiety and mental health of primiparous women. 2013.

17. Sharp H, Hill J, Hellier J, Pickles A. Maternal antenatal anxiety, postnatal stroking and emotional problems in children: outcomes predicted from pre-and postnatal programming hypotheses. Psychol Med. 2015;45(2):269-83.

18. Paloutzian RF, Ellison CW. Loneliness, spiritual well-being and the quality of life. Loneliness: A sourcebook of current theory, research and therapy. 1982:224-37.

19. Farahaninia M, Abbasi M, Givarry A, Haqqani H. Spiritual health of nursing students and their views on spirituality and spiritual care of patients. Iran J Nurs. 2005;18(44):7-14.

20. Seyedfatemi N, Rezaei M, Givari A, Hoseini F. Pray for the spiritual health of cancer patients. Payesh J. 2006;5(4):295-304.

21. Asghari A, Saed F, Dibajnia P. Psychometric properties of the Depression Anxiety Stress Scales-21 (DASS-21) in a non-clinical Iranian sample. Int J Psychol. 2008;2(2):82-102.

22. Samani S, Jokar B. Validity and reliability short-form version of the depression, anxiety and stress. 2001.

23. Sherer M, Maddux JE, Mercandante B, Prentice-Dunn S, Jacobs B, Rogers RW. The self-efficacy scale: construction and validation. Psychol Rep. 1982;51(2):663-71.

24. Barati S. Assessment simple and multiple relationships between self-esteem and self-efficacy and academic performance of students in the third year of the new system of secondary city of Ahvaz [MSc thesis]. Ahvaz: University of Chamran 2000:38-40.

25. Purtaghi G, Pakpour A. Happiness, self-efficacy and academic achievement among students of Baqiyatallah University of Medical Sciences. J Med Educ Dev. 2014;7(13):45-56.
26. Li R, Yin T, Fang F, Li Q, Chen J, Wang Y, et al. Potential risks of SARS-Cov-2 infection on reproductive health. Reprod BioMed Online. 2020;41:89-95.

27. Fakari FR, Simbar M. Coronavirus Pandemic and Worries during Pregnancy; a Letter to Editor. Arch Acad Emerg Med. 2020;8(1).

28. Rezaei M, Seyedfatemi N, Hosseini F. Spiritual well-being in cancer patients who undergo chemotherapy. Hayat. 2008;14.

29. Mehrabi T, Alijanpoor Aghamaleki M, Hosseiny RS, Ziraki Dana A, Safaee Z. A study on the relationship between spiritual wellbeing and quality of life in infertile women referred to infertility centers in Isfahan. J Urmia Nurs Midwifery Fac. 2014;12(7):562-7.

30. McCoubrie RC, Davies AN. Is there a correlation between spirituality and anxiety and depression in patients with advanced cancer? Support Care Cancer. 2006;14(4):379-85.

31. Salehi L, Rahimzadeh M, Molaei E, Zaheri H, Esmaelzadeh-Saeieh S. The relationship among fear and anxiety of COVID-19, pregnancy experience, and mental health disorder in pregnant women: a structural equation model. Brain Behav. 1835:e1835.

32. Adegbola M. Spirituality, self-efficacy, and quality of life among adults with sickle cell disease. South Online J Nurs Res. 2011;11(1).

33. Reicks M, Mills J, Henry H. Qualitative study of spirituality in a weight loss program: contribution to self-efficacy and locus of control. J Nutr Educ Behav. 2004;36(1):13-9.

34. Imam SS, Nurullah AS, Makol-Abdul PR, Rahman SA, Noon HM. Spiritual and psychological health of Malaysian youths. Research in the Social Scientific Study of Religion, Volume 20, Brill, Netherlands.

35. Wastnedge EA, Reynolds RM, van Boeckel SR, Stock SJ, Denison F, Maybin JA, et al. Pregnancy and COVID-19. Physiol Rev. 2020.

36. Ayora AF, Soler LM, Gasch AC. Analysis of two questionnaires on quality of life of chronic obstructive pulmonary disease patients. Rev Lat Am Enfermagem. 2019;27.

37. Farrell T, Reagu S, Mohan S, Elmidany R, Qaddoura F, Ahmed EE, et al. The impact of the COVID-19 pandemic on the perinatal mental health of women. J Perinat Med. /j/jpme. ahead-of-print/jpm2020-0415/jpm-2020-0415. xml.

38. Durankuş F, Aksu E. Effects of the COVID-19 pandemic on anxiety and depressive symptoms in pregnant women: a preliminary study. J Matern Fetal Neonatal Med. 2020:1-7.

39. Wu Y-T, Zhang C, Liu H, Duan C-C, Li C, Fan J-X, et al. Perinatal depression of women along with 2019 Novel Coronavirus Breakout in China. 2020.

40. Di Mascio D, Sen C, Saccone G, Galindo A, Grünebaum A, Yoshimatsu J, et al. Risk factors associated with adverse fetal outcomes in pregnancies affected by Coronavirus disease 2019 (COVID-19): a secondary analysis of the WAPM study on COVID-19. J Perinat Med. /j/jpme. ahead-of-print/jpm-20200355/jpm-2020-0355. xml.

Publisher's Note Springer Nature remains neutral with regard to jurisdictional claims in published maps and institutional affiliations. 